\title{
Determinants of Key Account Management Effectiveness: The Case of Ethio Telecom
}

\author{
Dires Abebe*
}

\begin{abstract}
Key account management (KAM) is one of the contemporary ways of maintaining enhanced relationships with strategic business customers named as 'key accounts'. It helps to build a strategic relationship particularly in businessto-business marketing. But 'what factors determine KAM effectiveness' is not much investigated. So, this study aims to address the determinants of key account management effectiveness in the context of Ethio Telecom. A conceptual model of factors that affect KAM effectiveness was developed and hypothesized. The hypotheses were tested with data collected from key account department of Ethio Telecom using structural equation modeling. The findings of this study show that from the postulated seven determinants of KAM effectiveness (strategy, solution, people, management, screening, government, and culture), the three (solution, management, and screening) were found significant determinants. The scope of the study is limited to a single telecom operator company in Ethiopia and analyzed from the perspective of the supplier. The findings provide the empirical application of the KAM model theorized by Zupancic (2008) by incorporating two additional external factors proposed to determine KAM effectiveness. The study contributes to the improvement of KAM implementation in Ethio Telecom particularly.
\end{abstract}

Keywords: Key Accounts, Key Accounts Management, Key Accounts Management Dimensions, Ethio Telecom

http://dx.doi.org/10.4314/ejbe.v5i1.5

*Sales Specialist, Ethio Telecom, Key Accounts Department, Addis Ababa, Ethiopia, Email: diresabebe@gmail.com, Mobile: +251911510459 


\section{Introduction}

These days the business endeavor has called for enhanced relationship between suppliers and customers. Companies are paying their efforts on treating their customers. Key account management is one mechanism of treating strategic business customers called 'key accounts'. According to Millman and Wilson (1995, p.9), these are customers in a business-to-business market identified by a selling company based on their strategic importance. They are most important customers with whom it is crucial to develop and maintain an added value relationship.

KAM is a customer oriented approach in the modern relationship marketing arena that focuses on the supplier's major customers (Ojasalo, 2000). It is an important marketing strategy to identify, select, analyze and manage the most important corporate customers of a company (Zupancic 2008). So it is basically designed to serve customers by discriminating among themselves in terms of their strategic importance and profitability (Millman and Wilson, 1995). According to Jobber and Lancaster (2009), the discrimination may take the form of special pricing, customization of products, provision of special services, customization of services, and information sharing. Macdonald and Woodburn (2007) also pointed that, some kind of differentiation is obligatory for key customers.

KAM helps to understand the characteristics and needs of key customers so as to serve as well as optimize the relationship. It plays a strategic role in building close relationships between supplier and customer organizations that add superior value to the customer's as well as to the supplier's business (Macdonald and Woodburn, 2007).

Accordingly, KAM has become a common practice in business-to-business interaction in most of the companies of the developed countries. It has attracted growing attention from both academics and sales and marketing practitioners 
in recent years (Baddar and Brennan, 2009). According to Zupancic (2008), the idea of KAM is more than 30 years old and the degree of professionalization both in research and practice has risen over time.

However, according to Baddar and Brennan (2009), the concept is still relatively immature among companies of the developing countries and the term is used to refer to too many customers who have no actual strategic significance to the companies. Such difficulty is observed due to the prevalence of the knowledge gap and lack of experiences in the area. Although there are no researches in Ethio Telecom in this case, the company may not be exceptional from these problems.

In addition to this, the adoption of KAM frameworks and models for the improvement of KAM effectiveness is also poor. In Ethio Telecom, no applicable KAM framework is adopted. The factors that determine the effectiveness of KAM are not identified. This may probably hurt the relationships of the company and the key accounts. Due to this, its performance and profitability may be affected negatively. As Workman et al. (2003) pointed out, KAM effectiveness has a direct effect on performance (which includes achieving customer satisfaction and providing value for customers) in the market that then leads to profitability.

Different researchers have identified determinants of KAM effectiveness that are proposed to improve KAM implementation effectiveness. The two models which are developed by Zupancic (2008) and Workman and Homburg and Jensen (2003,) are particularly substantial to mention. The former identified five determinants while the latter identified four formal determinants of KAM effectiveness.

Both of these models essentially focused on internal/organizational factors. But external factors are also likely to affect the success of KAM. Therefore, this study aimed at examining the determinants of KAM effectiveness in the 
context of Ethio Telecom based on those models; but by considering the external factors. The case study company introduced KAM approach with the consultation of France Telecom recently (in 2010), and this research may represent a benchmark study of KAM implementation.

\section{Literature Review}

Zupancic had developed five dimensions of KAM: strategy, solution, people, management and screening. In his framework, 'strategy' encompasses the activity of analyzing the information about the key accounts and competitors serving the same key account and then realizing the strategy of how the company should serve the key account.

'Solution' involves analyzing the special needs of the key accounts concerning the range of products and services, the current products and services being delivered to them, and then realizing a customized and/or an innovative solution (products and services) to add value and to realize the chosen strategy people deal with the skills, personal development programs, career- paths of the personnel.

According to Zupancic, 'people' deal with the skills, personal development programs, career- paths of the personnel. 'Management' deals with the analysis of the current way of working with key accounts, leadership approach with the people involved in KAM, and the realization of processes to serve key accounts. Screening deals with KAM effectiveness measuring systems, knowledge management, KAM effectiveness supporting tools, and flow of information. 


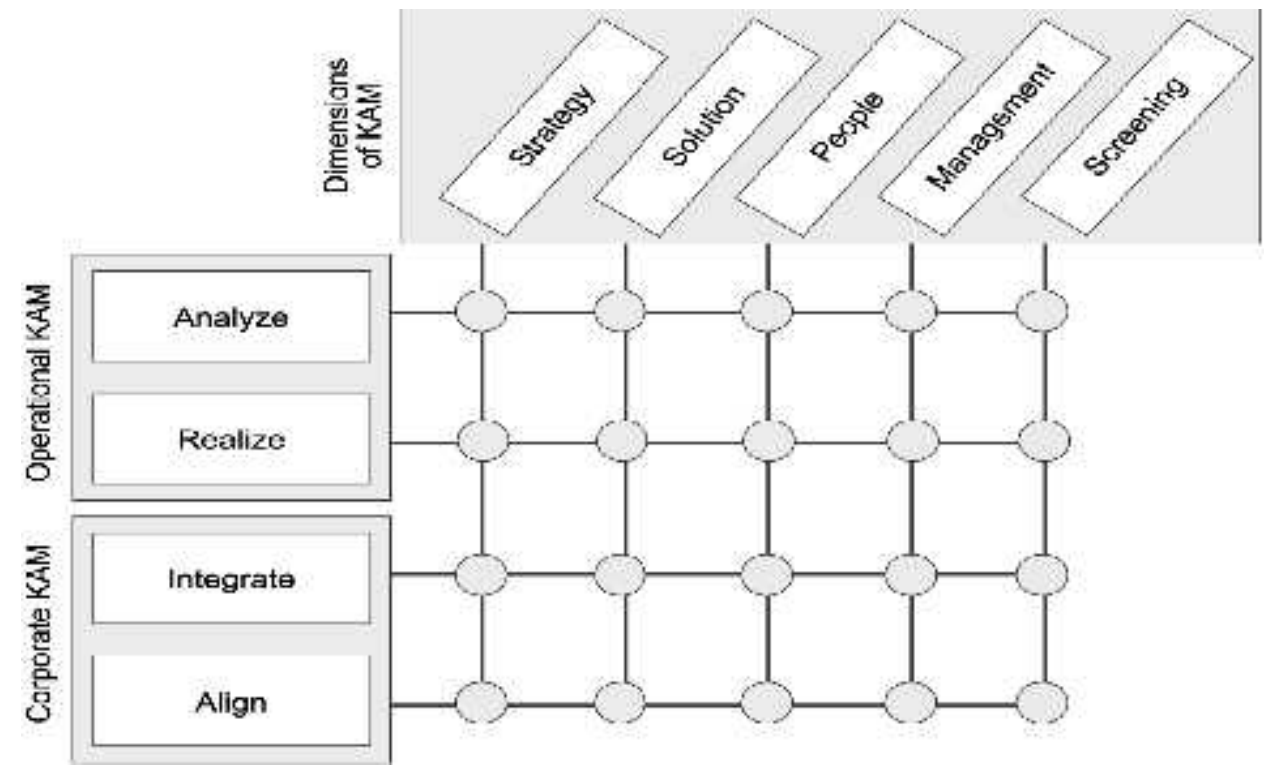

Figure 1: KAM framework (source: Zupancic 2008, p.326) 
As depicted in the figure above, Zupancic formulated his framework based on operational and corporate KAM approach. This is similar to Ojasolo's study who concluded that successful KAM requires appropriate handling at both the organizational and the individual levels Ojasalo (2001, p. 199).

In the figure, each dimension (strategy, solution, people management and screening) is crossed with the elements of the operational and corporate KAM (analyze, realize, integrate and align). This is based on the argument that operational and corporate KAM address different target groups (key account managers/teams and the corporate management) both can be provided with substantial support for their task. Key account managers and their teams will be supported with a kind of management process that covers the analysis of the relationship and the realization of a management process for KAM. The top management on the other side will be supported with a full overview of the levers a company can use to implement and optimize KAM.

Another model on KAM dimension is that of Workman et al. (2003) model. Here, there are four dimensions of KAM: 'activities', 'actors', 'resources' and 'formalization'. These dimensions are hypothesized to explain KAM effectiveness in the model. The dimension of 'activities' is further divided into activity intensity and activity proactiveness. Activity intensity refers to the extent to which additional activities are performed for key accounts. The types of activities are grouped under the $4 \mathrm{P}$ framework (i.e., product, pricing, promotion, and place), with the addition of communication and information sharing. Activity proactiveness, on the other hand, refers to the extent to which the supplier initiates activities.

Top management (involvement, support, and commitment) and use of KAM team (plan and coordinate for accounts solution) are considered as the 'actors' in the model. Under the dimension of 'resources', esprit de 
corps and access to marketing and sales resources are categorized. KAM esprit de corps is defined as the extent to which people involved in the management of key accounts feel obligated to common goals and to each other. It is related to the development of an organizational culture that supports customers. Access to marketing and sales resources is the extent to which a key account manager can obtain needed contributions to KAM from marketing and sales groups. The last dimension is 'formalization' which is defined as the extent to which an organization has established policies and procedures for handling its most important set of customers.

Finally, it may be important to compare and contrast the two models in such a way that, the second model is more general while the first one is more specific. For instance, 'strategy' and 'solutions' can be incorporated under the 'activates' dimension of Workman et al. as these are the major activities a supplier performs to its key accounts. 'People' dimension in Zupancic's model is the most important 'resource' of the supplier in Workman et al. model. The 'management' and the 'people' dimension in Zupancic's are the 'actors' in the Workman et al model. 'Screening' dimension is similar with 'formalization' dimension of Workman et al. model.

\section{Conceptual Framework}

This study uses the combination of the models constructed by Zupancic (2008) and Workman et al. (2003). Except the two extended variables (government and cultural influences) developed to consider external factors and to customize the model in the context of Ethio Telecom, all the other dimensions (the exogenous variables) are adopted from Zupancic. 'KAM effectiveness', which is the endogenous variable, is taken from Workman et al. (2003).

These models were supported by other researchers. Zupancic's model, for 
instance, is supported by Kruger (2011), Nordberg (2011), and by Management Center Europe (MCE, 2013). Ihsan (2011) and Badder and Brennan (2011) also use the model of Workman et al. (2003) for further investigation. For instance, MCE identified modified dimensions of KAM specifically: strategy, people, management, organization, measurement, process and tools. In this case, the modified dimensions are organization, measurement, process and tools. But 'Organization' and 'processes' can be incorporated under 'management' dimension in Zupancic's KAM framework and 'measurement' and 'tools' can be incorporated in 'screening'.

Zupancic (2008, p.329) argues that the better a company fulfills each of the elements, the better the performance of its KAM program. This study preferred to use 'KAM effectiveness' instead of 'KAM performance' as the former is widely used in KAM literature such as by Workman et al. (2003). It is also a well defined concept in KAM. So Zupancic's argument will be tested by taking his dimensions as the determinants of KAM effectiveness, as it has not yet been tested empirically. Accordingly, the following modified model as well as hypotheses were formulated to test the applicability of the framework. 


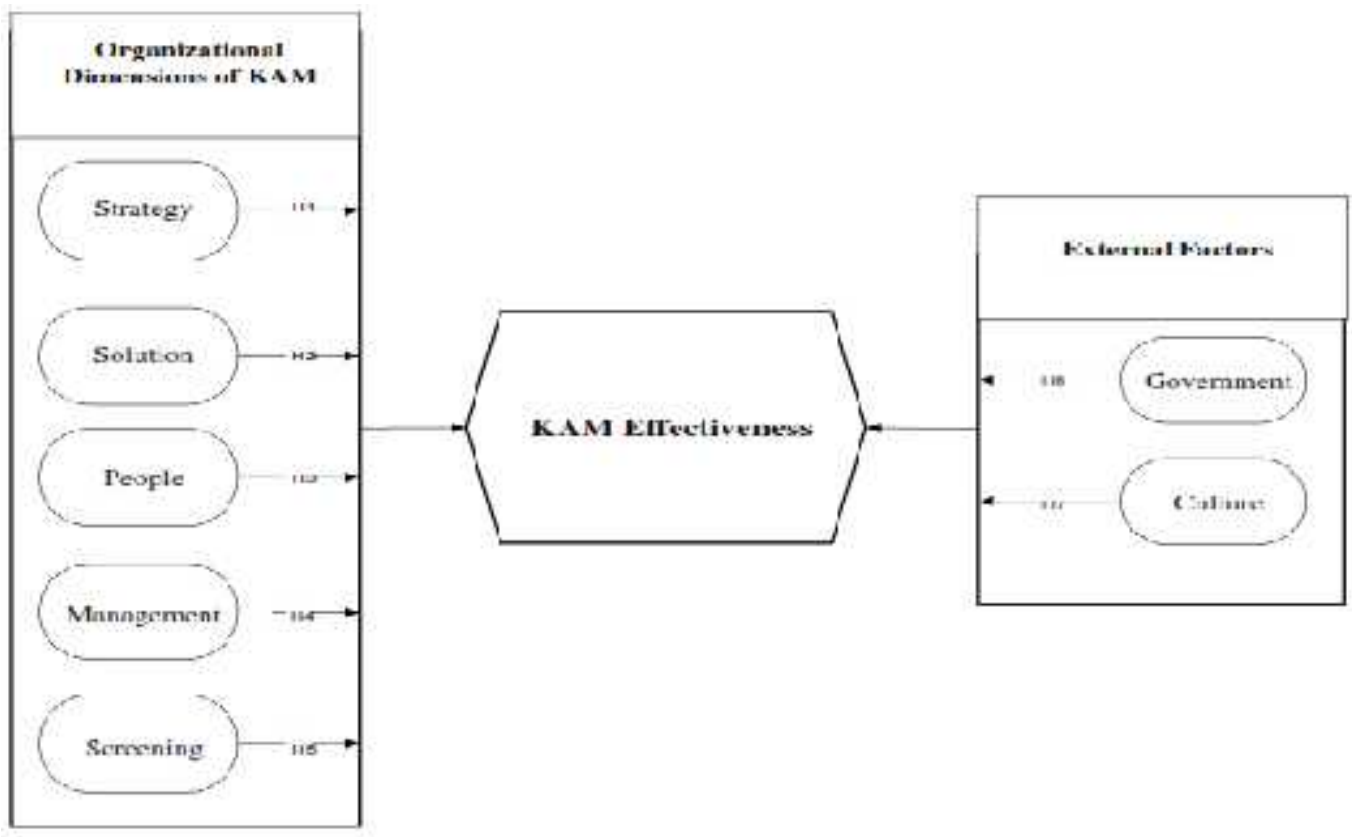

Figure 2: Hypothesized Determinants of KAM Effectiveness: A Modified Conceptual Model Based on Zupancic (2008) and Workman et al. (2003) KAM Model

\subsection{Hypothesized Determinants of KAM}

\section{A. Strategy}

Strategy refers to the specific choices a business will make to achieve a desired outcome, Kruger (2011, p.21). So KAM strategy is the means by which suppliers' objectives on KAM are achieved. In Zupancic's model, strategy covers both specific strategies for the selected key accounts and the strategies which focus on KAM within the overall corporate strategy. Key account management requires suppliers to deliver customized, innovative strategies to customers (Macdonald and Woodburn 2007). Kruger (2011) pointed out that strategy to invest in the business's own competencies, accounts knowledge and relationships with them is believed to determine KAM effectiveness.

In a nutshell, corporate KAM strategic plan, customized and/or innovative 
strategies, investment on key accounts' knowledge and relationships, and the marketing strategies related to product changes, price adjustments, IMC, and place of sales determines the effectiveness of KAM. So,

\section{$H_{1}$. Strategy positively and significantly determines KAM effectiveness.}

\section{B. Solutions}

The dimension of 'solution' starts with the clear understanding of customer needs and product requirements and then offering of customized solutions and innovations (Zupancic, 2008 and Kruger, 2011). According to Zupancic (2008: p.327), solution is the process of analyzing the special needs of the key accounts concerning the own range of products and services, the current products and services being delivered to them, and then realizing a customized and/or an innovative solution (products and services ) to add value and to realize the chosen strategy.

Customers require business solutions (offers) that can be applicable, appropriate and affordable. According to Baddar and Brennan (2009), the job of the KAM is to solve all the customer's problems, to act as a consultant not as a sales person, to create the need for the customer, to propose to the client business ideas that represent business solutions. Genuine KAM reaches deep inside a company to come up with the kind of breadth of offer and innovation that these key accounts seek (McDonalds and Woodburn, 2007, p. 28). Therefore, the higher the capacity of a supplier to deliver solutions and treatments, the more successful will be the KAM approaches.

\section{$H_{2 .}$ Solution positively and significantly determines KAM effectiveness.}

\section{People}

In Zupancic's model people deal with the skills, personal development 
programs, and career paths of the personnel. It defines the people's requirements to service the key account which includes the competency requirements, selection, training requirements and the view of management on the importance of key account people within the organization (Zupancic, 2008 and Kruger, 2011). The 'people' in KAM units consist of the key account management team that includes the key account manager and the sales executives.

As cited by Badder and Brennan (2009), McDonalds \& Rogers (1998: p. 120) provide a profile of the skills and qualities of the ideal account manager that fulfill the expectations of both the selling and buying companies. These skills and qualities are divided into four categories: personal qualities; subject knowledge; thinking skills; and managerial skills. Therefore, the personal skill of the personnel (key account manager and sales executives and other players in KAM unit); product knowledge; compensation, benefit, and carrier path programs of the company; competency requirements, recruitment and selection process; and trainings determine KAM effectiveness. And it is hypothesized as:

\section{H3. People positively and significantly determine KAM effectiveness.}

\section{Management}

Management includes aspects like structure, processes and coordination (Zupancic, 2008; Millman and Wilson, 1999). In his framework, Zupancic defined it as the analysis of the current way of working with key accounts, leadership approach with the people involved in KAM, and the realization of processes to serve key accounts. According to Kruger (2011), it involves the processes required to manage key accounts, the internal coordination of resources, the formalizing of structures and remuneration policies for key account personnel. 
So, key account management units should receive sufficient support from top level management (Brady, 2004,). Workman et al. (2003) also found that the relationship between top management involvement and KAM effectiveness is significant. Top executives need to be also committed to the management of the firm's most strategic customers (Guesalaga, 2007: p.5). Generally, senior managements' involvement, support, commitment, leadership approach, ability to motivate staffs, ability to allocate and coordinate resources, formalization of organizational structure, processes, and relationship with key accounts affects KAM effectiveness. On the basis of this logic, it can be hypothesized as:

\section{H4. Management positively and significantly determines KAM} effectiveness.

\section{E. Screening}

Screening deals with KAM effectiveness measuring systems, knowledge management, KAM effectiveness supporting tools, and flow of information. According to Kruger (2011), screening involves the processes and system requirements to measure KAM progress, protection of knowledge and reporting systems.

Thus, standard key accounts selection criteria, KAM profitability measurement systems, key accounts' satisfaction measurement systems, key accounts' performance assessment, existence of supporting tools, and the means of information flow determines KAM effectiveness. On the basis of these considerations, the below hypothesis is postulated.

$H_{5 .}$ Screening positively and significantly determines KAM effectiveness.

\subsection{Modified Determinants of KAM}

KAM is not only influenced by the above listed internal or organizational factors. But also by external or environmental factors (Homburg et al., 
2002). These are moderators that affect the strength of the link between organizational factors and KAM effectiveness. These include competitors, government, culture, technology, and the economy (Ihsan, 201: p.80).

In this study government and cultural influences are proposed to affect the link between organizational factors and KAM effectiveness. Other factors such as competition, technology and economic factors are excluded intentionally, thinking that their effect is insignificant.

\section{F. Government}

The impact of government influence on KAM effectiveness may be important to be studied along with the organizational factors. As a governmentally owned company, the influence of government on Ethio Telecom's KAM implementation may be significant. Government may intervene in each activity of the company for its different motive and KAM will not be exceptional. Government as a powerful customer, its interest and regulations on KAM approach are considered to determine KAM effectiveness. Understanding this, it is possible to hypothesize the following:

\section{H. Government indirectly and significantly determines KAM effectiveness.}

\section{G. Culture}

The second environmental factor posited to moderate the relationship between organizational factors and KAM effectiveness is 'culture'. The culture of the customers: such as business (marketing) knowledge, values and attitudes, manners and customs, material elements, education and social institutions can affect KAM implementation. So these elements may have a major impact on a number of key account management related issues, including how relationships start and develop, buyer-seller interactions, business networks, business negotiations, buying-decision processes in the 
buyer's organizations, selling styles, personal and institutional credibility, and sales force management (Ihsan, 2011: p.80). On the basis of this logic, it is hypothesized as:

\section{H7. Culture indirectly and significantly determines KAM effectiveness.}

\section{Research Design}

Structured survey questionnaire was designed to collect objective data using Likert scales with five anchors ranging from 'strongly disagree' to 'strongly agree'. With this method the empirical application of the conceptual model of KAM effectiveness was tested hypothetically taking the case of Ethio Telecom. For this, a case-study approach was selected because of its empirical enquiry that investigates a contemporary phenomenon within its real life context, especially when the boundaries between phenomenon and context are not clearly evident (Yin, 1994, cited by Krznaric \& Popovski, 2000: p.17). And Ethio Telecom was selected since it adopted key account management approach as a result of the transformation made from 2010 to 2013 with the support of one of the leading telecom operators in the world-France Telecom.

The questionnaire contained two parts. The first part is designed to collect respondents' background information. It includes questions about their education which may have an effect on their understanding of KAM approach, about their service year that helps to capture their experiences in managing and serving key accounts, about their position in KAM to know whether their role can affect KAM effectiveness, and the group of key accounts they serve to know if there are differences of KAM effectiveness across these segments.

The second part is the structured questions designed to measure each dimension and the dependent variable. The structured questionnaire items 
were adopted and developed based on the definitions given in the literatures by Zupancic (2008), Jones (2000), Irving (1995), Workman et al. (2003), Kruger (2011), Gounaries and Tzempeikos (2012) and Macdonald and Woodburn (2007). These items were designed to explain each of the independent variables (strategy, solution, people, management, screening, government influences and socio-cultural influences) and the dependent variable (KAM effectiveness). Except the items for the dependent variable, which were totally adopted from Irving (1995), all other items of the independent variables were developed based on the definitions and explanations given by the above mentioned researchers.

Totally 49 items were developed to describe both the independent and dependent variables with five-point Likert scale $(1=$ strongly disagree to $5=$ strongly agree) to prove each hypothesis. With this, the first three research questions will be addressed. The ultimate goal of the structured questions is to get objective literature based answers.

The target population of this study consists of the key players of KAM in Ethio Telecom. It includes those in the management position and the nonmanagers of the department of key account management. The department, headed by Executive Officer, is responsible to coordinate key account managers. The key account managers headed each of the above listed sectors and coordinates sales executives. Sales executives have given the responsibility of acting as the single point of contact within Ethio Telecom for each account.

The total size of the population, which comprises the officer; key account managers; and sales executives is about 48. Since this is too easy to manage, census is the technique used to conclude the study.

From the total respondents, 38 of them responded in the given time and thus the response rate became $79 \%$. From this, 35 were considered valid and 
were used in the final analysis. The 3 were eliminated because of some errors in filling the structured question. From those who successfully responded, 32 were sales executives and the rest 3 were managers.

\section{Measurement Reliability and Validity}

A construct is said to be reliable or consistent if it brings same result when we use it multiple times (Bhattacherjee 2012). Since we used multiple-item construct measure to the respondents, the extent to which respondents rate those items in a similar manner or in short the 'internal consistency' was estimated after the survey by including all the items. The internal consistency of the scale items was computed using the commonly applicable method called Cronbach alpha. Thus, the overall reliability of the scale was found to be 0.915 (Table 1) which indicates the acceptability of the items.

Partially, the scale consistency of the dimensions adopted from Zupancic (2008) namely: strategy, solution, people, management and screening is 0.914. Each of these scored 0.709, 0.545, 0.752, 0.879 and 0.801 respectively. The extended new dimensions of government and culture are estimated to be 0.686 and 0.871 respectively.

To assure the construct validity, that is whether our measure adequately represents the underlying supposed to measure, theoretical assessment of validity was undertaken. Accordingly, the items were partially adopted from previous studies and partially based on the definitions given by different researchers listed above. Besides, appropriate research procedures were applied to find the answers to the basic question. With this the construct validity is also assured. 
Determinants of Key Account Management Effectiveness

Table 1: Scale Reliability with Cronbach's Alpha

\begin{tabular}{|l|l|l|}
\hline Dimensions & $\begin{array}{l}\text { Cronbach's } \\
\text { Inho }\end{array}$ & No. of Items \\
\hline Strategy & 0.709 & 7 \\
\hline Solution & 0.545 & 5 \\
\hline People & 0.752 & 5 \\
\hline Management & 0.859 & 10 \\
\hline Screening & 0.801 & 8 \\
\hline Government & 0.686 & 5 \\
\hline Culture & 0.871 & 3 \\
\hline KAM Effectiveness & 0.771 & 6 \\
\hline Overall Scale & $\mathbf{0 . 9 1 5}$ & $\mathbf{4 9}$ \\
\hline
\end{tabular}

Source: Survey questionnaire

The data collected using the structured questionnaire were analyzed using different statistical tools in line with the research objectives. Assisted by the SPSS (version 20) package, descriptive statistics such as frequency, mean, skewness and kurtosis were used to explain the importance of each dimension as rated by the respondents, to check normal distribution respectively.

The inferential statistics were also used to test the hypotheses and to answer the research questions raised, such as to measure associations between the dependent and the independent variables and the impact of independent variables on the dependent variable. Correlation was used to explore the association of independent variables (strategy, solution, people, management, screening, government and culture) with the dependent variable (KAM effectiveness). Multiple linear regression was used to analyze the impact of each factor on KAM effectiveness. 


\section{Findings and Discussions}

\subsection{Descriptive Analysis}

It may be important to see the mean score of respondents from each of the segments of the key accounts. For instance, as shown in table 2 below, most of the respondents from financial institutions accept the importance of 'strategy' (approximately strongly agree, mean= 4.714). Totally, respondents were slightly above the extent of 'agree' for the importance of strategy, solution, people, management and screening with a mean score of $4.40,4.46,4.36,4.38$, and 4.15 respectively in determining KAM effectiveness.

Unfortunately, the extended external factors namely: government and culture gained mean scores between the extent of 'neutral' and 'agree' which implies that respondents are either uncertain or have moderate attitudes towards the impact of these factors on KAM effectiveness. Cumulatively, the two factors scored means of 3.62 and 3.96 respectively. The detail of the mean score each KAM dimension across the different section is depicted in the table below. 
Determinants of Key Account Management Effectiveness

Table 2: Means of KAM Effectiveness and its Dimensions

\begin{tabular}{|c|c|c|c|c|c|c|c|c|}
\hline $\begin{array}{l}\text { Responient's } \\
\text { Sircticn }\end{array}$ & Strategy & Solutien & Peuple & Management & Strevinimg & Guveriment & Culture & $\begin{array}{l}\text { KAM } \\
\text { Ellectiveness }\end{array}$ \\
\hline $\begin{array}{l}\text { Financial } \\
\text { Instirutiors }\end{array}$ & 4.71 & 4.56 & 4.48 & 156 & 1.25 & 4.2 & 3.2 & 1.6 \\
\hline 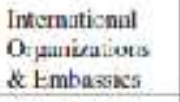 & $4 .(2)$ & 4.36 & $4 . / 2$ & 452 & 4.38 & 4.12 & $4.4 i$ & 463 \\
\hline $\begin{array}{l}\text { Government } \\
\text { Adaninistration }\end{array}$ & 4.43 & 4.48 & 4.28 & 156 & 1.28 & 3.96 & 4.2 & 4.73 \\
\hline $\begin{array}{l}\text { Public } \\
\text { Entarprises }\end{array}$ & 4.35 & 4,6 & 4.5 & 1.6 & 4.35 & 3.25 & 4.12 & 71 \\
\hline $\begin{array}{l}\text { Private } \\
\text { Siervicn } \\
\text { Enterprise }\end{array}$ & 1.1 & 4.4 & 1.08 & 101 & 3.82 & 3.28 & 1.05 & 421 \\
\hline $\begin{array}{l}\text { Complex \& } \\
\text { Special } \\
\text { Projocts }\end{array}$ & 4.4 & 4.33 & 4.2 & 4.28 & 4.09 & 3.03 & 3.89 & 4.25 \\
\hline $\begin{array}{l}\text { Prociuction \& } \\
\text { Industries }\end{array}$ & 4.17 & 4.27 & 1.17 & 1.3 & 4 & 3.67 & 3,33 & 4.33 \\
\hline Total & 4.4 & 4.46 & 4.36 & 4.38 & 4.15 & 3.62 & 3.96 & 448 \\
\hline
\end{tabular}

\subsection{Correlation Analysis}

Pearson correlation ( $r$ ) coefficient was applied to detect the relationship between variables. This was undertaken after checking the normal distribution. Accordingly, KAM effectiveness was found significantly associated with all KAM dimensions except strategy and the extended external dimensions at $\mathrm{p}<0.01$. As shown in table 3 below, the correlation coefficient ranges from the lower coefficient value of solution (0.544) to the higher value of management dimension (0.633). People and screening are also associated significantly (at $\mathrm{p}<0.01)$ with KAM effectiveness with coefficient values of 0.552 and 0.553 respectively.

Significant correlation coefficient values were also detected between each of the predictors. For instance, strategy was found to be related with solution and people with coefficient values of 0.637 and 0.51 at $p<0.01$ and with management and screening with values of 0.416 and 0.344 at $\mathrm{p}<0.05$ respectively. Likewise, the relationship of management with people 
(0.704) and screening (0.599) was found significant at $\mathrm{p}<0.01$ and with strategy $(0.416)$ and solution $(0.428)$ at $p<0.05$ significance level. The detail is depicted in table 3 below.

Yet, significant association was not detected between government in one side and the remaining KAM dimensions (including the external variable culture) on the other side. Culture, on the other hand, was found related with people dimension $(0.372)$ at $\mathrm{p}<0.05$ significance level.

\section{Table3: Pearson correlations coefficients}

\begin{tabular}{|c|c|c|c|c|c|c|c|}
\hline Variables & $\begin{array}{l}\text { KAM } \\
\text { Fffectiveness }\end{array}$ & Strategy & Solution & Penple & Management & Screening & Ginvernment \\
\hline Strategy & .323 & & & & & & \\
\hline Solution & $.544^{t 2 x}$ & $637^{* 11}$ & & & & & \\
\hline People & $.552^{*: *}$ & $510^{\text {th }}$ & $-448^{\text {m: }}$ & & & & \\
\hline Management & $.633 * 8$ & $416^{*}$ & $.428^{\circ}$ & $.704^{4}: *$ & & & \\
\hline Screening & .553 *a & $344^{*}$ & $.403^{*}$ & $.515^{\text {tes }}$ & $599 * *$ & & \\
\hline Government & .216 & 192 & .177 & .273 & .259 & .107 & \\
\hline Culture & .078 & 301 & .261 & $.372 *$ & 188 & .174 & .023 \\
\hline
\end{tabular}

Snurce: Survey questionuaine

Noies: *-Correlation is significant at the $2.0 I$ lewd 2 -failed, *-Correlation is significant at the 0.05 level i2-kaileúl.

\subsection{Regression Analysis}

According to Daniel, L. (1991, p.421), a correlation between two variables does not imply that one event causes the second to occur. Therefore, to know how the dimensions of KAM and the external variables determine KAM effectiveness and thus to test the hypotheses, multiple regression was carried out.

After checking normality of distribution, independency of residuals and multi-collinearity; multiple regression was carried out. A stepwise multiple linear regression method was followed to get the smallest possible set of predictors in the model. Besides, to obtain a weighted least- squares 
model, data points from the different sections of the respondents were weighted by the reciprocal of their variances. This makes the observations with large variances to have less impact on the analysis than observations associated with small variances.

The independent variables estimated to predict KAM effectiveness were strategy, solution, people, management, screening, and the other two external variables: government and culture. Using all these predictors, the stepwise multiple regression analysis resulted in three models. In the first model, the only significant predictor variable found at $\mathrm{p}<0.05$ was management (model 1- table 10). This model explained $41 \%$ of the variance (Adjusted $\mathrm{R}$ square $=0.414$ and $\mathrm{R}$ square=0.431) (Table 5). All other variables namely: strategy, solution, people, screening, government and culture were excluded.

In the second model (step 2 of table 5), solution was found as a significant additional predictor together with management. The inclusion of solution into the model resulted in $7 \%$ (adjusted $\mathrm{R}$ square=0.482) increase into the variance being explained $(\mathrm{R}$ square $=0.513)$. 
Determinants of Key Account Management Effectiveness

Table 5: Regression Coefficients

\begin{tabular}{|c|c|c|c|c|c|c|c|c|}
\hline \multirow[t]{2}{*}{ Model } & \multirow[t]{2}{*}{ Predictars } & \multirow{2}{*}{$\begin{array}{l}\text { Unstandardized } \\
\text { Coeffirients } \\
\text { B }\end{array}$} & \multirow{2}{*}{$\begin{array}{l}\text { Standardized } \\
\text { Coefficients } \\
\text { Std. Errar }\end{array}$} & \multirow[t]{2}{*}{ Beta } & \multirow[t]{2}{*}{ T.value } & \multirow[t]{2}{*}{ Sig. } & \multicolumn{2}{|c|}{ Collimearify Statistic } \\
\hline & & & & & & & Tolerance & VIF \\
\hline \multirow[t]{2}{*}{1} & (Constant) & 1.437 & 596 & & 2412 & .022 & & \\
\hline & Management & 687 & 137 & 657 & 5.002 & 000 & 1000 & 1000 \\
\hline \multirow[t]{3}{*}{2} & (Conatart) & 124 & 798 & & 155 & 878 & & \\
\hline & Mamagement & .546 & 143 & 521 & 3.818 & 001 & $B 16$ & 1.225 \\
\hline & Soluton & 436 & 189 & 376 & 2311 & 027 & 816 & 1.225 \\
\hline \multirow[t]{4}{*}{3} & (Constant) & .007 & 763 & & -009 & 993 & & \\
\hline & Wanagement & 375 & 159 & 359 & 2.357 & .025 & 597 & 1.675 \\
\hline & Soluxon & 383 & .182 & 277 & 2109 & .043 & 800 & 1250 \\
\hline & Screenus & 269 & 130 & 304 & 2066 & 041 & 639 & 1.566 \\
\hline
\end{tabular}

Souriz. Sancy quivaliomatio

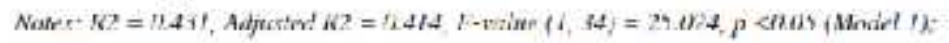

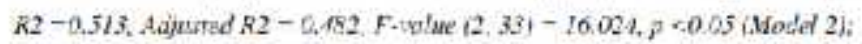

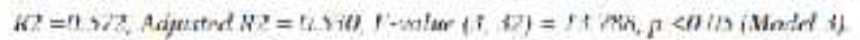

The final model (model 3) included screening to the set of the significant predictors (management and solution) at $\mathrm{p}<0.05$ significance level. This model accounted for $53 \%$ (adjusted $\mathrm{R}$ square $=0.53, \mathrm{R}$ square $=0.572$ and $\mathrm{R}$ square change $=0.059$ ) of the variance and increased the variance explained by $5 \%$. In the ANOVA table the significance value of the $\mathrm{F}$ statistic was found to be 0.000 which is less than 0.05 . It means that the variation explained by the model is not due to chance. This also shows that there is a significanct relationship between the independent variables and the dependent variable. The strength of the relationship is based on the R statistic, which is 0.756 indicating a strong relationship.

Consequently, from all the seven predictors, in three steps, the regression analysis reached at three significant factors (solution, management and screening at $\mathrm{p}<0.05$ significance level, $\mathrm{t}$ - value all greater than the suggested value, i.e., 1.96) which were hypothesized as determinants of KAM 
effectiveness. From the three significance predictors, solution $(\beta=0.383)$ emerged as the most important determinant of KAM effectiveness, management $(\beta=0.375)$ appeared second, and screening $(\beta=0.269)$ third. Thus the three hypotheses, namely: H2, H4 and H5 postulated for solution, management and screening respectively get supported.

On the other hand, the remaining four (strategy, people, government and culture) variables were found insignificant $(p>0.05)$ to determine KAM effectiveness. Subsequently, H1, H3, H6 and H7 that posit strategy, people, government and culture determine KAM effectiveness failed to get supported.

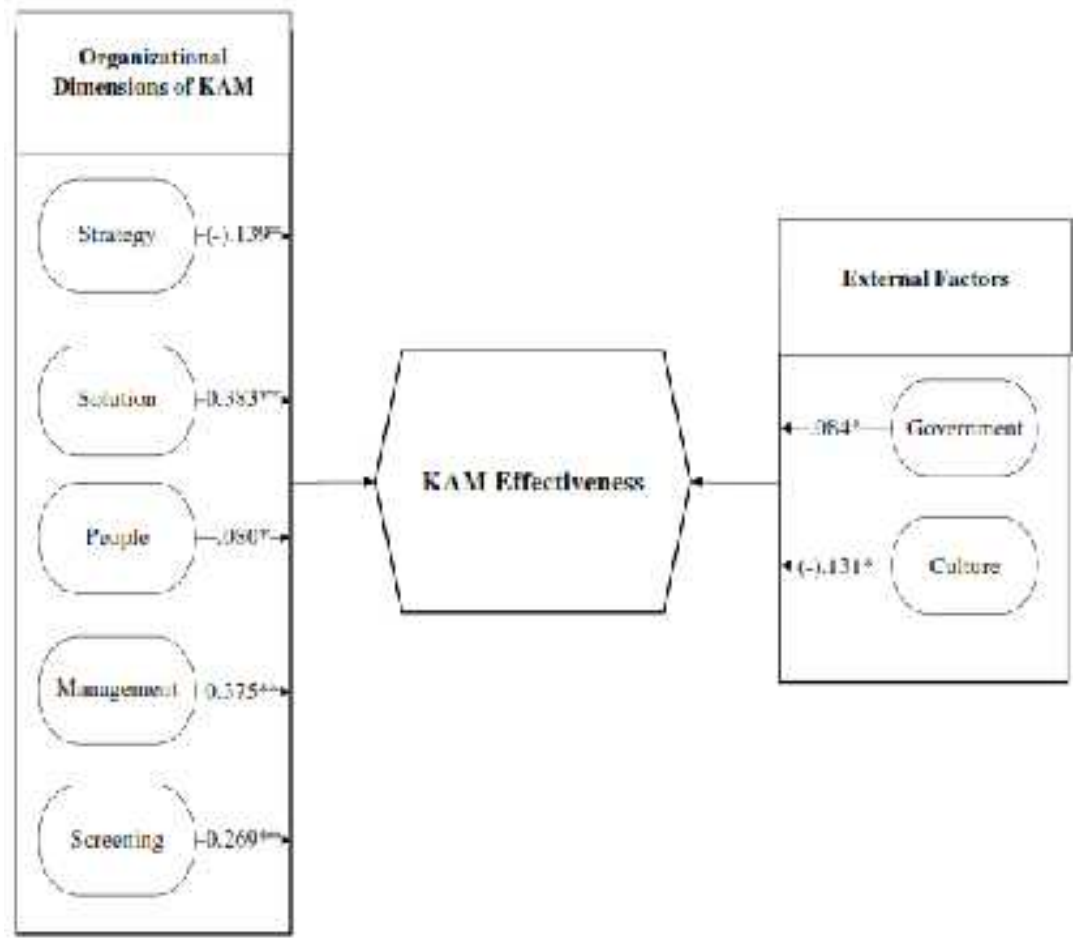

Figure 3: Results of Hypothesis Testing ( $\mathrm{N}=35)$

Notes: $R$ Square $=0.572$, Adjusted $R$ Square $=0.53, F$-value $=13.788, p<0.05$ (Model 3)

$* \mathrm{p}>0.05=$ insignificant $* * \mathrm{p}<0.05=$ significant 
Determinants of Key Account Management Effectiveness

\section{Conclusion}

The primary objective of the study was to examine the determinants of key account management effectiveness in the context of Ethio Telecom. Accordingly, five organizational KAM dimensions (strategy, solution, people, management and screening) and other two additional external factors (government and culture) were hypothesized to determine KAM effectiveness. The descriptive statistics show that all the independent variables, except the two additional external variables, scored a cumulative mean greater than 4.15 as measured using a five-point Likert type scale. This implies that these variables are important in determining KAM effectiveness.

Considering this report, correlation statistics was undergone to check the relationship with KAM effectiveness (dependent variable). Then, it was assured that significance association existed between KAM effectiveness and solution, management, people and screening. But KAM effectiveness has no significance association with strategy and with the extended external factors. The independent variables are also interrelated except the additional factors. Particularly, the stronger association of people and management indicates their interdependence.

To investigate whether the independent variables determine KAM effectiveness, regression was carried out. Thereby, it was revealed that solution, management and screening are the significant $($ at $* * p<0.05)$ dimensions that positively determine KAM effectiveness. These variables explained 53 percent of the variation in KAM effectiveness and are 75.6 percent related.

\subsection{Implications}

As drawn in the conclusion; solution, management and screening determine KAM effectiveness significantly. Considering this, KAM practitioners 
Determinants of Key Account Management Effectiveness

particularly the case company's top and middle managers as well as the key players in the key account department- key account managers and sales executives shall do specifically the below mentioned activities.

Firstly, key account managers and sales executives should identify and analyze their key accounts' requirements, special needs, problems and areas of dissatisfactions then proactively respond immediate and appropriate solutions through customization and/or innovation.

Secondly, the management should actively involve, support, and be committed enough in managing key accounts. Formalized KAM organizational structure and working processes shall be designed. A leadership approach that improves the relationship with key accounts should be also followed. It should also develop the capability of allocating and coordinating resources and the ability to motivate the dedicated key account management team. The personnel are very much dependent on the management's support, active involvement, and motivational factors.

Lastly, activities related to screening such as setting standard key accounts selection and deselecting criteria, reviewing key accounts portfolio, adopting KAM performance and key accounts' satisfaction measurement tools, availing supporting tools, and ensuring flow of information should be done for KAM to be effective.

\subsection{Limitations and Direction for Future Study}

This study tried to examine the determinants of KAM from the supplier's point of view only. But a different result can be found from the customers' point of view. So this may be a future area of problem to be investigated.

In addition, the applicability of KAM model can be better tested by increasing the sample size through including other companies that have adopted the 
approach. Because, our limited number of population certainly affected the result found.

Further tests on the applicability of the KAM model shall be also conducted by incorporating more items and factors that possibly explain KAM effectiveness since our model only covers 53 percent of the variation in the dependent variable. For instance, some authors considered the positive effect of 'competition' on KAM from external factors.

Regarding our second objective, evaluating company practice, also better result might be gained using additional data collection tools such as interview and by incorporating middle and top managers and also other supporting units such as marketing and network divisions. Therefore, these things should be considered in future researches. 
Determinants of Key Account Management Effectiveness

\section{References}

Aasland, A. (2009). A User Manual for SPSS Analysis. Oslo: Norwegian Institute for Urban and Regional Research.

Addis Ababa University School of Commerce. (n.d.). Guidline for Writing Thesis. Unpublished.

Baddar, F. \& Bernnan, R. (2009). Strategic account management in an emerging economy. Journal of Business \& Industrial Marketing, 611 -620 .

Bhattacherjee, A. (2012). Social Science Research: Principles, Methods, and Practices. Florida: Creative Commons Attribution.

Brehmer, P. \&. (2009). Proactive and Reactive Drivers for Key Account Management Programmes. European Journal of Marketing Vol. 43 No. $7 / 8$.

Cheverton, P. (2008). Key Account Management Tools and Techniques for Achieving Profitable Key Supplier Status. London and Philadelphia: Kogan Page Limited.

Daniel, L. (1991). Reference Guide on Multiple RegressionBerkeley. Berkeley: University of California.

Ellis, T. \&. (2008). Framework of Problem-Based Research: A Guide for Novice Researchers on the Development of a Research Worthy Problem. the International Journal of an Emerging Trans discipline Vol. 11, 17-33.

Ethio Telecom. (2011). Enterprise Marketing strategy. Unpublished. Ethio Telecom. (2011). Marketing Plan for Enterprise Division. Unpublished. Gounaris, S. \&. (2012). Conceptualization and Measurement of Key Account Management Orientation.

Guesalaga, D. (2007). Top Management Involvement with Key Accounts: The Concept, Its Dimensions, and Strategic Outcomes. Unpublished Doctoral Dissertation in the Pennsylvania State University.

Ihsan, Z. (2011). Key Account Management in an Arab Context,. Unpublished Doctoral Dissertation in Cranfield University School of Management.

Jobber, D. \&. (2009). Selling and Sales Management. London: Pearson Education.

Jones, R. (2000). The Key Account Manager's Pocketbook. London: Management Pocketbooks Ltd. 
Determinants of Key Account Management Effectiveness

Kruger, E. (2011). the Development of a Blueprint for a Key Account Management Strategy to Differentiate Businesses in the Liquid Beverage

Industry Businesses. Unpublished Masters Thesis at the University of Stellenbosch.

Krznaric, D. \&. (2001). Key Account Management in an International Context. Unpublished Master Thesis at Goteborg University.

Lane, P. a. (2006). the Hidden Risks In Strategic Account Management Strategy. Journal of Business Strategy Vol. 27.

Management Center Europe. (2013). Strategic Key Account Management.

www.mce-ama.com. McDonald, M. \&. (2008). Key account management: The definitive Guide. Oxford: Butterworth-Heinemann.

Millman, T. \&. (1995). From Key Account Selling To Key Account Management. Journal of Marketing Practice: Applied Marketing Science, Vol. 1 No. 1, , 9-21.

Millman, T. \&. (1996). Developing key account management competences. Journal of Marketing Practice: Applied Marketing Science, Vol. 2 No. 2, 7-22.

Murray, S. (2006). a Dyadic Trust Perspective of Key Accounts Relationship Development in the United Kingdom Mortgage Industry. Doctoral Dissertation, University of Northumbria.

Negi, R. (2009). User's Perceived Pervice Quality of Mobile Communications: Experience from Ethiopia. International Journal of Quality \& Reliability Management Vol. 26 No. 7, pp.699-711.

Nordberg, S. (2011). Key Account Acquisition and Retention in the United Kingdom Private Medical Insurance Market Case Study: AXA PPP Healthcare. Unpublished Manuscript at Turku University of Applied Sciences.

Ojasalo, J. (2000). Key Account Management and Quality in Business-To -Business Relationship. Swedish School of Economics and Business Administration.

Ojasalo, J. (2001). Key Account Management at Company and Individual Levels in Business-to- Business Relationships. Swedish School of Economics and Business Administration. 
Determinants of Key Account Management Effectiveness

Pardo, C. \&. (2006). Unpicking the Meaning of Value in Key Account Management. European Journal of Marketing Vol. 40 No. 11/12 , 1360 -1374 .

Pardo, C. (1999). Key Account Management in the Business-To-Business Field: a French overview. Journal of Business \& Industrial Marketing, Vol. 14 No. 4, 276-290.

Pels, J. (1991). Identification and Management of key Clients . European Journal of Marketing, Vol. 25 No.5 .

Piercy, F. \&. (2006). the Hidden Risks In Strategic Account Management Strategy. Journal of Business Strategy Vol. 27.

Razzaq, A. (2012). Key Account Management Practices in Home Appliance Industry of Pakistan. Unpublished Manuscript at Blekinge Institute of Technology.

Richards, R. (2007). Relationship Effectiveness and Key Account Performance: Assessing Inter- Firm Fit between Buying and Selling Organizations. Unpublished Doctoral Dissertation at University of Houston.

Ryals, L. \&. (2007). Key Account Planning: Benefits, Barriers and Best Practice. Journal of Strategic Marketing, Volume 15, .

Sharma, A. (2006). Success Factors In Key Accounts . Journal of Business \& Industrial Marketing, 141-150.

Spencer, R. (2005). Strategic Management of Customer Relationships: A Network Perspective on Key Account Management. Uppsala University.

Vassiljeva, J. (2008). Introduction of Key Account Management Concept to the CRDS Organization. Unpublished Manuscript at the University of Applied Sciences of Bremen.

Vyas, H. (2013). Key Account Management. Indian Institute of Management.

Woodburn, D. (2009). organizing for Key Account Management. Research in action. Woodburn, D. (2011). Understanding Key Account Management. University of Glamorgan.

Workman, J. H. (2003). Intra Organizational Determinants of Key Account Management Effectiveness. Journal of the Academy of Marketing Science, 3-21.

Zupancic, D. (2008). Towards an Integrated Framework of Key Account Management. Journal of Business \& Industrial Marketing, 323-3. 